\title{
Detecting Atlantic herring by parametric sonar
}

\author{
Olav Rune Godø \\ Institute of Marine Research, P.O. Box 1870 Nordnes, 5817 Bergen, Norway \\ olavrune@imr.no \\ Kenneth G. Foote \\ Woods Hole Oceanographic Institution, Woods Hole, Massachusetts 02543 \\ kfoote@whoi.edu \\ Johnny Dybedal \\ Kongsberg Defence and Aerospace AS, P.O. Box 55, Strandveien 1, 7501 Stjørdal, Norway \\ johnny.dybedal@kongsberg.com \\ Eirik Tenningen and Ruben Patel \\ Institute of Marine Research, P.O. Box 1870 Nordnes, 5817 Bergen, Norway \\ eirik.tenningen@imr.no,ruben.patel@imr.no
}

\begin{abstract}
The difference-frequency band of the Kongsberg TOPAS PS18 parametric sub-bottom profiling sonar, nominally $1-6 \mathrm{kHz}$, is being used to observe Atlantic herring. Representative TOPAS echograms of herring layers and schools observed in situ in December 2008 and November 2009 are presented. These agree well with echograms of volume backscattering strength derived simultaneously with the narrowband Simrad EK60/18- and 38-kHz scientific echo sounder, also giving insight into herring avoidance behavior in relation to survey vessel passage. Progress in rendering the TOPAS echograms quantitative is described.

(C) 2010 Acoustical Society of America

PACS numbers: 43.30.Sf, 43.80.Jz, 43.80.Nd, 43.30.Lz [JL]

Date Received: December 16, 2009 Date Accepted: February 2, 2010
\end{abstract}

\section{Introduction}

Remote detection of fish by acoustics was demonstrated by Sund in $1935,{ }^{1}$ and ultrasonic acoustic surveys have been an integral part of scientific surveys of pelagic ${ }^{2}$ and benthopelagic ${ }^{3,4}$ fish stocks for over 30 years. Acoustic surveys are normally carried out at discrete frequencies in the band from 18 to $300 \mathrm{kHz}$.

Norwegian spring-spawning herring (Clupea harengus) is the largest existing herring stock, with an annual catch exceeding $1 \times 10^{6}$ tonnes. ${ }^{5}$ The stock is monitored annually with multiple-frequency acoustics using the Simrad EK60 scientific echo sounder operating at 18, 38, 70, 120 , and $200 \mathrm{kHz}$. During the period November-January, the herring winters off the northwest continental shelf of Norway, where the present study took place in 2008 and 2009.

Availability of the Kongsberg TOPAS PS18 Parametric Sub-bottom Profiler on board R/V “G. O. Sars" has encouraged examination of its potential for surveying herring ${ }^{6}$ as well as other fishes. This parametric sonar, with total difference-frequency band $0.5-6 \mathrm{kHz}$, may have several advantages. At its long wavelengths, $25-300 \mathrm{~cm}$, scattering is less sensitive to orientation effects, which are strong at the short wavelengths of ordinary ultrasonic frequencies used in surveying. ${ }^{7,8}$ It may also be possible to exploit strong or resonance scattering by the swimbladder-bearing herring, as has been done in other studies, ${ }^{9-13}$ to determine fish size, ${ }^{14}$ contributing to remote classification and avoiding biases associated with physical capture, as by pelagic trawling.

The immediate objectives of this study are (1) to demonstrate the ability of the TOPAS parametric sonar to detect herring in the water column and (2) to investigate the influence of the transmit signal waveform on the detection process. The larger project goal is to use parametric 
sonar to quantify pelagic fish such as herring. This involves determination of numerical density, as by echo integration, ${ }^{2}$ and the swimbladder-resonance frequency for remote sizing and other classification.

It is noted that the TOPAS echo data presented here have not been reduced to values of volume backscattering strength. This reduction is sufficiently complicated to require additional processing, which is outlined.

\section{Materials}

In December 2008 and November 2009, wintering of Norwegian spring-spawning herring was observed in the area (N71-72, E14-17). The behavior was different in the two years: the herring formed layers, or shoals, in December 2008, but distinct schools in November 2009. The difference can be attributed to the one-month difference in time, with associated maturation effects.

The principal acoustic instrument used in this study was the Kongsberg TOPAS PS18 Parametric Sub-bottom Profiler. ${ }^{15}$ This parametric sonar, as a parametric acoustic array, ${ }^{16,17}$ is based on collinear transmission of powerful signals in the band $15-21 \mathrm{kHz}$. Because of the acoustic nonlinearity of water, the waves interact in the water column, forming a virtual endfire array that generates new waves, especially at the sum and difference frequencies. The difference-frequency wave is often exceptionally directional, with broad bandwidth and significant apparent secondary source level too, e.g., $204 \mathrm{~dB}$ re $1 \mu \mathrm{Pa}$ at $1 \mathrm{~m}$. In the case of TOPAS, the nominal difference-frequency band is $0.5-6 \mathrm{kHz}$, with beamwidths in the approximate range $3-5$ deg. The beam can also be steered over a wide sector. Scattered difference-frequency waves are received and detected conventionally with part of the TOPAS transducer.

In December 2008, the presence of herring in a shoal or layer enabled the acoustic measurements to be made without the need for hunting tactics. In November 2009, the presence of herring in rather small compact schools required use of a horizontal multibeam sonar, the Simrad SP70 Fish Finding Sonar, operating in the band 20-30 kHz, to track schools, and vesselmaneuvering to pass over them.

During both cruises, the observed herring was sampled with a pelagic trawl. Conductivity-temperature-depth profiles were also taken to obtain information about sound speed. The observation and sampling platform during both cruises was R/V "G. O. Sars," a 4000-gross-tonne research vessel built in 2003.

\section{Methods}

Herring have been observed routinely by sonar including echo sounders operating at ultrasonic frequencies since the 1950s, ${ }^{18}$ with well-developed methodology for measuring its numerical density. This methodology has been applied here based on the Simrad EK60 scientific echo sounder operating at $18,38,70,120,200$, and $333 \mathrm{kHz} .{ }^{19}$ The split-beam transducer beamwidths at 18 and $38 \mathrm{kHz}$ were 11 and $7 \mathrm{deg}$, respectively, with both transmitting sinusoidal signals in 1-ms bursts.

The initial observations were made on 7 December 2008 at position (N71.4, E16.3) with bottom depth exceeding $1000 \mathrm{~m}$. The TOPAS and EK60 were operated simultaneously at a nominal, constant ping rate of $1 \mathrm{ping} / \mathrm{s}$, but without use of an external trigger signal. The phase of the TOPAS was adjusted to avoid interference in the vicinity of the herring layer. The observations were made both with the vessel drifting freely and with the vessel sailing at its ordinary survey speed of $5 \mathrm{~m} / \mathrm{s}$.

During the period 13-18 November 2009, the herring was observed in the middle of the ongoing fishery at roughly (N71, E15). The TOPAS and EK60 were again operated simultaneously, but with use of an external trigger signal and phasing sufficient to avoid interference in the upper $500 \mathrm{~m}$. Because of the presence of herring in rather small schools, the SP70 was used for tracking, and the vessel was maneuvered to maximize the chances of passing directly over the schools. The vessel speed was typically in the range $1.5-4 \mathrm{~m} / \mathrm{s}$. The bottom depth was approximately $1500-2500 \mathrm{~m}$. 

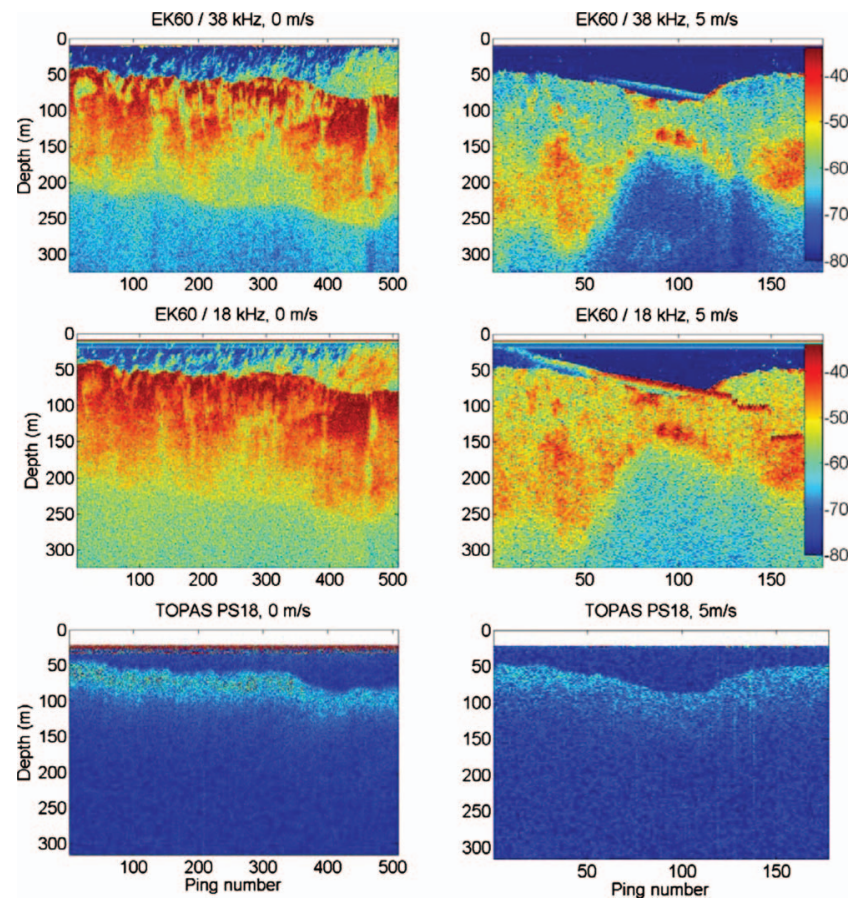

Fig. 1. Two sets of concurrent echograms of Norwegian spring-spawning herring in its wintering area near (N71.4, E16.3) observed from R/V “G. O. Sars" on 7 December 2008. The left set was obtained while the vessel was drifting freely; the right set was obtained with the vessel sailing at the ordinary survey speed of $5 \mathrm{~m} / \mathrm{s}$. Echograms obtained with the Simrad EK60 scientific echo sounder display values of the volume backscattering strength in decibels according to the attached color bar. The echograms derived with the Kongsberg TOPAS PS18 Parametric Sub-bottom Profiler involved transmission of a 16-ms FM signal with linear frequency dependence over the band 1-6 kHz, with sampling at $30 \mathrm{kHz}$ after a 20 -ms trigger delay, represented by the blank area at the top of the echogram. These data have not been processed, lacking both range compensation and calibration. All echograms were derived from measurements made with proximate transducers with vertically downward oriented beams. In the EK60 echograms collected at $5 \mathrm{~m} / \mathrm{s}$, there are extraneous signals, probably second bottom echoes, appearing at the surface and descending through the herring records.

\section{Results and discussion}

\subsection{First cruise, December 2008}

Representative echograms of herring collected simultaneously with the TOPAS parametric sonar and EK60/18- and 38-kHz scientific echo sounders on 7 December 2008 are shown in Fig. 1. A pelagic trawl taken at the same position yielded a catch dominated by herring, lengths $28-36 \mathrm{~cm}$, with mean $32.5 \mathrm{~cm}$. The basic similarity in corresponding echograms, especially with respect to the upper surface of the herring layer, demonstrates that the differencefrequency band of TOPAS can detect herring aggregations in the midwater column. Other echo data collected simultaneously during this cruise with the EK60 and TOPAS demonstrate the detection of herring by TOPAS at least to $200 \mathrm{~m}$.

The similarity in detected upper surfaces of the herring layers is also revealing of herring behavior. Typically, herring respond to the passage of survey vessels by diving and moving away from the vessel path. ${ }^{20,21}$ Given that the beamwidth of the TOPAS differencefrequency beam is of order 3-5 deg, while the beamwidths of the EK60/18 and $38 \mathrm{kHz}$ transducers are 11 and $7 \mathrm{deg}$, respectively, a differential effect in diving and horizontal movement should be detectable, at least to the order of the narrowest beam diameter at the upper surface, about $4 \mathrm{~m}$. The absence of an effect suggests that the behavior is largely unaffected by passage of the vessel. 
There are also differences in the TOPAS echograms relative to the EK60 echograms. A major difference is the apparently weaker echo response with increasing depth in the herring layer. This is interesting because the difference-frequency pressure field is still developing at ranges where the herring layer is being measured, while the beamwidth is decreasing. However, the TOPAS echograms have not been compensated for range, while the EK60 echograms have been increased according to the ordinary function used for volume backscattering, discussed further in Sec. 4.3.

It may be wondered whether the observed TOPAS echo response is consistent with the phenomenon of swimbladder resonance, with enhanced frequency-selective scattering at the kilohertz difference-frequencies of TOPAS. Since herring cannot inflate its swimbladder underwater, the gas-filled sac will decrease with increasing pressure. Effects on backscattering are relatively well known at ultrasonic frequencies, ${ }^{22}$ but much less so at the mentioned kilohertz frequencies, although the swimbladder is expected to dominate the scattering in both frequency regimes. ${ }^{9,14,23}$ The depth and depth history are expected to influence the backscattering to a significant degree. At higher, ultrasonic frequencies, the elongated form of the herring swimbladder, with flattened deformation against the spinal vertebrae under compression, ${ }^{24}$ precludes strong resonance scattering. ${ }^{25}$

As an aside, the EK60 echograms in Fig. 1 reveal an interesting phenomenon. Strong, patchy scattering above the upper surface of the layer is believed to be due to individual herring migrating to the sea surface to fill their swimbladder. ${ }^{26}$

\subsection{Second cruise, November 2009}

During the period 13-18 November 2009, the TOPAS PS18 parametric sonar was used with the EK60 scientific echo sounder to observe herring in small schools off the northwest coast of Norway. To aid the process of detection with vertically oriented transducer beams, the SP70 sonar was used to track schools from horizontal ranges extending to about $1500 \mathrm{~m}$.

The schools were so numerous at the beginning of the cruise that it was a relatively simple matter of following an arbitrary transect to pass over these. Later, the schools dispersed, and the opportunity was seized to observe the same school repeatedly. Detections with four different TOPAS waveforms are demonstrated in Fig. 2: a $20 \mathrm{~ms}$ duration frequency-modulated (FM) pulse spanning the frequency band $1-6 \mathrm{kHz}$, and three continuous-wave (cw) pulses, each with four cycles, at 6,3 , and $1.5 \mathrm{kHz}$, respectively. Herring schools were also detected at intermediate frequencies as well as at $1.2 \mathrm{kHz}$. A pelagic trawl taken in the vicinity of the observations reported in Fig. 2 yielded exclusively herring, length $15.5-37.5 \mathrm{~cm}$, mean $30.5 \mathrm{~cm}$.

Detection at lower frequencies, which could be useful vis-à-vis swimbladderresonance excitation, requires further work. The ambient noise is rather high at such frequencies, while the parametric array itself is less efficient at generating low difference-frequency signals, since the intensity varies as the fourth power of the difference frequency. ${ }^{17}$

Again, a basic similarity in form, especially with respect to the upper surface of the schools, is evident when comparing TOPAS echograms with the corresponding EK60/18-kHz echograms. As in the case of the herring layers in 2008, the herring schools do not display differential avoidance effects to within the width of the narrow TOPAS beam at the upper surface of the schools.

\subsection{Future work}

The accomplishment of this work is demonstration of the ability of the TOPAS parametric sonar to detect herring in the water column using a variety of transmit signals. The larger goal of the work, using the parametric sonar to quantify pelagic fish such as herring, is now being pursued. The envisioned quantification involves determination of numerical density, as by echo integration, ${ }^{2}$ and determination of the swimbladder-resonance frequency for remote sizing and other classification.

The two essential requirements for quantification have already been defined. ${ }^{27,28}$ The parametric sonar echoes must be compensated for range to remove simple geometric scattering effects, as is done routinely with conventional sonars. ${ }^{2,29,30}$ This is relatively complicated in the 

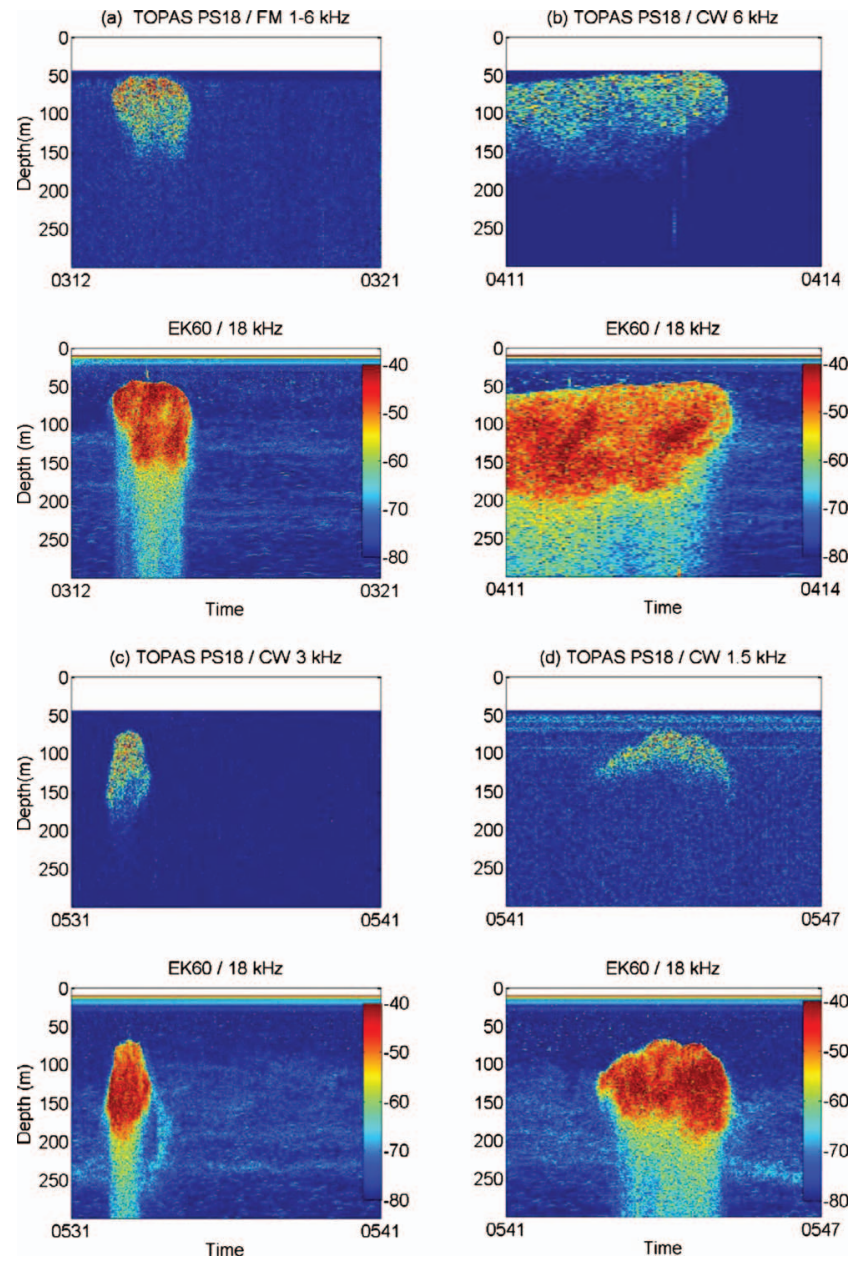

Fig. 2. Echograms collected on the same school of Norwegian spring-spawning herring in its wintering area near (N71.3, E15) on 15 November 2009 during repeated passes with R/V "G. O. Sars" while sailing at $5 \mathrm{~m} / \mathrm{s}$. Upper panel: Echograms obtained with the TOPAS PS18 parametric sonar, expressed as raw values without range compensation, for each of four transmit signals, with frequency band indicated for the 20-ms duration linear FM signal and with center frequency indicated for the 4-cycle cw burst. Echo data were sampled at $25 \mathrm{kHz}$ following a 50 -ms trigger delay, represented by the blank area at the top of the echogram. The TOPAS echoes have been processed by matched filtering for the FM signal and bandpass filtering for the $\mathrm{cw}$ signals. Lower panel: Respective echograms obtained with the EK60/18-kHz scientific echo sounder, with 1-ms duration transmission at $18-\mathrm{kHz}$, expressed as values of volume backscattering strength.

case of parametric sonar because the difference-frequency field increases with range in the nearfield, while the difference-frequency beamwidth decreases. ${ }^{28}$ The range compensation function for expression of TOPAS data as relative values of volume backscattering strength has been described and evaluated numerically in a separate study.

The parametric sonar also requires calibration. The standard-target method $\mathrm{d}^{31,32}$ is being adapted for parametric sonar. The first calibration trial was conducted on 10 December 2008. Echoes from a $280-\mathrm{mm}$-diameter solid sphere of an aluminum alloy ${ }^{33}$ were measured at each of three depths with a variety of transmit signal waveforms ${ }^{27}$ The target position is being determined by simultaneous observations with the EK60/18- and $38-\mathrm{kHz}$ scientific echo sounder, whose split-beam transducers are located in the vicinity of the TOPAS transducer. This will enable TOPAS echoes to be expressed in physical scattering units of volume backscattering 
When the range compensation function and calibration data from TOPAS are available, the echo spectrum will be examined. The use of both broadband FM signals and a series of narrowband $\mathrm{CW}$ signals will enable a strong comparison to be made.

The same TOPAS data will also be compared with data collected simultaneously with the ultrasonic EK60 scientific echo sounder. This will prove the consistency and potential usefulness of parametric sonar for quantification of swimbladder-bearing fish in the very region where the parametric beam is being formed.

\section{Acknowledgments}

Work supported by the Norwegian Research Council under Grant No. 184705 and the Office of Naval Research under Award No. N000140910482.

\section{References and links}

${ }^{1}$ O. Sund, "Echo sounding in fisheries research," Nature (London) 135, 953 (1935).

${ }^{2}$ D. N. MacLennan, "Acoustical measurement of fish abundance," J. Acoust. Soc. Am. 87, 1-15 (1990).

${ }^{3}$ O. R. Godø and V. G. Wespestad, "Monitoring changes in abundance of gadoids with varying availability to trawl and acoustic surveys," ICES J. Mar. Sci. 50, 39-51 (1993).

${ }^{4}$ W. A. Karp and G. E. Walters, "Survey assessment of semi-pelagic gadoids: The example of walleye pollock, Theragra chalcogramma, in the Eastern Bering Sea," Mar. Fish. Rev. 56, 8-22 (1994).

${ }^{5} \mathrm{R}$. Toresen and O. J. Østvedt, "Variation in abundance of Norwegian spring-spawning herring (Clupea harengus, Clupeidae) throughout the 20th century and the influence of climatic fluctuations," Fish Fish. 1, 231-256 (2000).

${ }^{6}$ O. R. Godø, K. G. Foote, J. Dybedal, and E. Tenningen, “Observing Atlantic herring by parametric sonar,” J. Acoust. Soc. Am. 125, 2718 (2009).

${ }^{7}$ O. Nakken and K. Olsen, “Target strength measurements of fish,” Rapp. P.-V. Reun.-Cons. Int. Explor. Mer 170, 52-69 (1977).

${ }^{8}$ L. Midttun, "Fish and other organisms as acoustic targets," Rapp. P.-V. Reun.-Cons. Int. Explor. Mer 184, 25-33 (1984).

${ }^{9}$ D. V. Holliday, "Resonance structure in echoes from schooled pelagic fish," J. Acoust. Soc. Am. 51, 1322-1332 (1972).

${ }^{10}$ O. Diachok, "Effects of absorptivity due to fish on transmission loss in shallow water," J. Acoust. Soc. Am. 105, 2107-2128 (1999).

${ }^{11}$ O. Diachok, "Absorption spectroscopy: A new approach to estimation of biomass," Fish. Res. 47, 231-244 (2000).

${ }^{12}$ N. C. Makris, P. Ratilal, D. T. Symonds, S. Jagannathan, S. Lee, and R. W. Nero, "Fish population and behavior revealed by instantaneous continental shelf-scale imaging," Science 311, 660-663 (2006).

${ }^{13}$ J. S. M. Rusby, M. L. Somers, J. Revie, B. S. McCartney, and A. R. Stubbs, "Experimental survey of a herring fishery by long-range sonar," Mar. Biol. (Berlin) 22, 271-292 (1973).

${ }^{14}$ A. Løvik and J. M. Hovem, "Experimental investigation of swimbladder resonance in fishes," J. Acoust. Soc. Am. 66, 850-854 (1979).

${ }^{15}$ J. Dybedal, "TOPAS: Parametric end-fire array used in offshore applications," in Advances in Nonlinear Acoustics, edited by H. Hobæk (World Scientific, Singapore, 1993), pp. 264-275.

${ }^{16}$ P. J. Westervelt, "Parametric acoustic array," J. Acoust. Soc. Am. 35, 535-537 (1963).

${ }^{17}$ M. B. Moffett and W. L. Konrad, "Nonlinear sources and receivers," in Encyclopedia of Acoustics, edited by M. J. Crocker (Wiley, New York, 1997), pp. 607-617.

${ }^{18} \mathrm{O}$. Dragesund, J. Hamre, and Ø. Ulltang, "Biology and population dynamics of the Norwegian spring-spawning herring," Rapp. P.-V. Reun.-Cons. Int. Explor. Mer 177, 43-71 (1980).

${ }^{19}$ L. N. Andersen, "The new Simrad EK60 scientific echo sounder system," J. Acoust. Soc. Am. 109, 2336 (2001).

${ }^{20}$ E. Ona, O. R. Godø, N. O. Handegard, V. Hjellvik, R. Patel, and G. Pedersen, "Silent research vessels are not quiet," J. Acoust. Soc. Am. 121, EL145-EL150 (2007).

${ }^{21}$ K. Olsen, J. Angell, F. Pettersen, and A. Løvik, "Observed fish reactions to a surveying vessel with special reference to herring, cod, capelin and polar cod," FAO Fish. Rep. 300, 131-138 (1983).

${ }^{22}$ E. Ona, X. Zhao, I. Svellingen, and J. E. Fosseidengen, "Seasonal variation in herring target strength," in Herring: Expectations for a New Millenium, edited by F. Funk, J. Blackburn, D. Hay, A. J. Paul, R. Stephenson, R. Toresen, and D. Witherell (University of Alaska Sea Grant College Program, Fairbanks, AK, 2001), pp. $461-487$.

${ }^{23}$ K. G. Foote, "Importance of the swimbladder in acoustic scattering by fish: A comparison of gadoid and mackerel target strengths," J. Acoust. Soc. Am. 67, 2084-2089 (1980).

${ }^{24} \mathrm{E}$. Ona, "Physiological factors causing natural variations in acoustic target strength of fish," J. Mar. Biol. Assoc. U.K. 70, 107-127 (1990).

${ }^{25}$ D. T. I. Francis and K. G. Foote, "Depth-dependent target strengths of gadoids by the boundary-element method," J. Acoust. Soc. Am. 114, 3136-3146 (2003). 
${ }^{26}$ J. H. S. Blaxter and R. S. Batty, "The herring swimbladder-Loss and gain of gas,” J. Mar. Biol. Assoc. U.K. 64, 441-459 (1984).

${ }^{27}$ K. G. Foote, J. Dybedal, and E. Tenningen, "Standard-target calibration of a parametric sonar over the differencefrequency band, 1-6 kilohertz (A)," J. Acoust. Soc. Am. 125, 2718 (2009).

${ }^{28} \mathrm{~K}$. G. Foote, "Range compensation function for echo integration in transducer near fields, with special reference to parametric sonar (A)," J. Acoust. Soc. Am. 125, 2718 (2009).

${ }^{29} \mathrm{~S}$. T. Forbes and O. Nakken, "Manual of methods for fisheries resource survey and appraisal. Part 2. The use of acoustic instruments for fish detection and abundance estimation," FAO Man. Fish. Sci. 5, 1-138 (1972).

${ }^{30}$ R. B. Mitson, Fisheries Sonar (Fishing News Book Ltd., Farnham, Surrey, UK, 1983).

${ }^{31}$ K. G. Foote, "Maintaining precision calibrations with optimal copper spheres," J. Acoust. Soc. Am. 73, 1054-1063 (1983).

${ }^{32}$ K. G. Foote, H. P. Knudsen, G. Vestnes, D. N. MacLennan, and E. J. Simmonds, "Calibration of acoustic instruments for fish density estimation: A practical guide,” ICES Coop. Res. Rep. 144, 1-69 (1987).

${ }^{33}$ K. G. Foote, D. T. I. Francis, and P. R. Atkins, "Calibration sphere for low-frequency parametric sonars," J. Acoust. Soc. Am. 121, 1482-1490 (2007). 